\title{
THE REFUSAL STRATEGIES EMPLOYED BY PRE-SERVICE EFL TEACHERS: A COMPARISON BETWEEN JAVANESE AND SUMATRANS
}

\author{
Lintang Indah Ayu Respati Dewi ${ }^{1}$, Lailatun Nurul Aniq ${ }^{2}$, Khairani Dian Anisa ${ }^{3}$ \\ ${ }^{1-3}$ Universitas Sebelas Maret, Indonesia
}

DOI: 10.23917/humaniora.v20i2.9924

Received: January $16^{\text {th }}, 2020$. Revised: May 17 ${ }^{\text {th }}, 2020$. Accepted: June $12^{\text {nd }}, 2020$

Available Online: August 29 ${ }^{\text {th }}$, 2020. Published Regulary: August, 2020

\begin{tabular}{ll}
\hline Keywords & Abstract \\
\hline DCT, & Refusing is a part of commissive speech acts. Refusing is a face- \\
EFL, & threatening act (FTA) that needs a good pragmatic competence \\
pragmatic compe- & since it probably gives risk to the interlocutor's positive or negative \\
tence, & face. However, it indicates that people from various cultural \\
refusal strategies, & backgrounds employ dissimilar refusal strategies. This study aimed \\
speech acts, & at providing a comparison of refusal strategies used between \\
& Javanese Pre-service English Teachers (JPETs) and Sumatranese \\
Corresponding & Pre-service English Teachers (SPETs) in accordance with different \\
Author & levels of power. The data were elicited from the DCT given to 10 \\
Aniqun Nurul & JPETs and 10 SPETs. The participants were asked to fill the DCTs \\
Universitas & with written responses in which each DCT described different \\
Sebelas Maret, & contexts and settings. Based on the analysis, JPETs and SPETs \\
Indonesia & employed similar strategies in refusing to a request. The difference \\
Email: & was only on the frequency usage of a certain strategy. Furthermore, \\
rul@stu- & all of the indirect strategies were applied to refuse a request \\
dent.uns.ac.id & meanwhile only a strategy comes from a direct strategy called the \\
Phone: & negation of proposition that is applied. A direct refusal strategy call \\
+6285799637690 & bluntness was not applied. This study evoked pre-service awareness \\
& of pragmatic competence which could be taught to their future \\
& students and larger participants were encouraged for future study.
\end{tabular}

\section{INTRODUCTION}

English has truly become a global language due to its rapid expansion all over the world. It seems like everyone should be able to speak English. English also has a label as lingua franca that means English has become a common means of communication of people who speak a different first language. Thus, the learner of English should be able to speak English correctly and naturally. It means that the learner is required to produce not only a grammatically correct sentence but also a sentence that suits a specific context in order to minimize the miscommunication during the interaction since a sentence may have some different meanings in different contexts. The learner should engage their pragmatic competence in their communication. The growth of EFL learners' pragmatic competence has been one of the central concerns for EFL teachers and curriculum designers so that the topic gets concerns from EFL researchers (Felix-Brasdefer, 2008). As a fair result of this interest, studies in interlanguage pragmatics have been examined broadly to investigate how EFL learners' pragmatic competence promotes over time and what influential 
factors are in this process. Interlanguage pragmatics itself can be termed as the study of how learners come to know how to say, what, to whom, and when (Bardovi-Harlig, 2013).

Studies conducted in this area using dissimilar elements of research design. Most of them dealt with a unique feature, i.e. their concentration on the recognition of speech acts by EFL/ESL learners (Demirkol, 2016). Speech acts are a famous topic for research concerning on pragmatic competence of learners since it is a communicative competence that has been recognizing by learners in their mother tongue and what learners are required to accomplish is merely for learning pragma-linguistic features and perform an appropriate form-function process in the target language (Kondo, 2008). Besides, the topic of speech acts has been broadly interested in researchers in this topic as its consequences for both hearer and speaker may be reduced or increased by social variables of power, distance, and ranking of imposition as proposed by Brown and Levinson (1987).

This trend inspired this research to specifically conduct one of speech acts, i.e. refusal in focus. Refusal act essentially is a face-threatening act in which the hearer's expectation(s) is not met so that her/his action freedom is impeded (Campilo, 2009). Refusal act falls to the category of directives and they require special instructional emphasis because learners need appropriate linguistic tools along with pragmatic awareness to express themselves satisfactorily while refusing due to its complex nature (Felix-Brasdefer, 2008). When one performs refusal act in a second language or a foreign language, refusal act seems to have become a serious challenge for ESL/EFL learners because of the difficulty of using this act properly in other cultures (Kondo, 2008). Refusal act appears as a response of a previous act, e.g. invitation, offer, request, or suggestion (Gass and Houck, 1999).

Various related studies have been done on the refusal act. Beebe, et. al. (1990) compared the refusal act performance from Japanese language native speakers and English native speakers by using a Discourse Completion Test (DCT). The DCT normally contains a structured written discourse part, i.e. providing both the speech act and the rejoinder (Cohen, 1995). Although the topic has a high popularity, an ongoing discussion about the advantages and disadvantages of the DCT has often occurred among academicians (Kasper and Dahl, 2001).

The DCT, for some researchers, gets criticism in which it may not indicate elements of natural conversations, e.g. paralinguistic elements, speaker-listener coordination, and turn-taking (Kasper, 2000). Furthermore, responses drawn out by the DCT is informed to be the indication of participants' awareness about what they have to say regarding contextual factors rather than turning indicators of their actual performance (Golato, 2003). Despite the existence of potential future debate, its usefulness has been recognized and it has grown their popularity as an instrument of data collection in this similar research area.

Campillo et al. (2009) in his research proposed a revised refusal taxonomy from Beebe, et al.'s (1990) taxonomy. He classified the refusal act taxonomy into two major categories, i.e. refusals and adjuncts to refusals. The refusal strategy divides into direct strategy and indirect strategy. The direct strategy involves bluntness and the negation of the proposition. The indirect strategy includes plain indirect, reason/explanation, regret/apology, alternative (change option or change time), disagreement/dissuasion/criticism, statement of philosophy, and avoidance. Adjuncts to refusals cover positive opinion, willingness, gratitude, agreement, solidarity/empathy.

While previous studies have exhibited that transfer happens at the pragmatic level, e.g. Beebe et al., (1990), the interrelationship between first language transfer and second language proficiency in interlanguage pragmatics has been arguable. It is crystal clear that studies on the phenomenon of pragmatic transfer, i.e. in the speech act of refusal, grow up. The interrelationship between first language pragmatic transfer and second language proficiency raises an issue for investigation (Codina-Espurz, 2013). The number of refusal act studies on how first language conventions influence the ESL/EFL learners' refusal performance, i.e., pragmatic transfer, are a few. Furthermore, previous studies comparing 
the speech act of refusals among cultural groups only involve some ethnic groups, e.g. Americans, Chinese, Koreans, Saudis, Japanese (Demirkol, 2016). Refusal performance of ESL/EFL learners from other cultures has obtained less interest.

Some related studies have examined the refusal performance of ESL/EFL learners from different cultures. Wijayanto (2019), for example, compared the performance of refusal strategies between Javanese language native speakers in Indonesia and British English native speakers in the United Kingdom. The data were drawn out through DCT. The findings indicated that both Javanese and British native speakers used indirect refusal strategies and employed closely similar sequential orders of refusals. Nevertheless, the types of semantic formulas and adjuncts engaged were different. Awareness of different social status levels indicated to stimulate dissimilar frequencies of the use of semantic formulas and adjuncts of refusals in which dissimilar previous acts of refusal act generated dissimilar use of the types of semantic formulas and adjuncts.

Besides comparing refusal strategies between Indonesian EFL students and English native speakers, Ilmiani, et al (2016) examined the refusal strategy between fifteen Indonesian EFL learners and fifteen Thailand EFL learners. Through DCT, the participants were required to refuse requests and suggestions from different status levels of the interlocutors. This study indicated that status levels of the interlocutors and the nature of the initiating acts of refusals determine the refusal strategy employed by both groups. Moreover, both groups used combined strategies of politeness to express refusal.

Another comparative study is conducted by Chojimah (2015). She investigated Indonesian university students in refusing offers, invitations, and suggestions from different social statuses interlocutors. 161 students verbally responded to the discourse completion test (DCT) provided. This study revealed that Indonesian prefer using an indirect manner in performing refusal strategies. In performing direct refusal, Indonesian students tend to combine some strategies to minimize face threatening acts. Moreover, social status determined the politeness strategies to use. The higher the status of the interlocutor, the more polite the expressions would be uttered to him/her are.

The present study focuses on an investigation of refusal strategies employed by Sumatranese and Javanese EFL pre-service teachers in refusing a request. It is primarily based on Campillo et. al.'s (2009) taxonomy. Specifically, this taxonomy has been suggested from a socio-pragmatic approach and a CA framework, in which issues, i.e. formality degree, politeness, and social variables are at interest. Besides, the three sociopragmatic features delivered in Brown and Levinson's (1987) politeness theory are applicable in the refusals studies since their face-threatening nature. Then, the study attempts to answer what refusal strategies are employed by Sumatranese and Javanese pre-service EFL teachers in refusing a request.

However, little researches study refusal strategies employed by different ethnic groups in Indonesia. The present study focuses on an investigation of refusal strategies employed by Sumatrans and Javanese EFL pre-service teachers in refusing a request. It is primarily based on Campillo et. al.'s (2009) taxonomy. Specifically, this taxonomy has been suggested from a socio-pragmatic approach and a CA framework, in which issues, i.e. formality degree, politeness, and social variables are at interest. In addition, the three socio-pragmatic features delivered in Brown and Levinson's (1987) politeness theory are applicable in the refusal studies since their face-threatening nature. The study attempts to answer (1) what are refusal strategies employed by Sumatrans and Javanese pre-service EFL teachers in refusing requests and suggestions? and (2) does social status level influence the selection of refusal strategies produced by Sumatrans and Javanese pre-service EFL teachers? 


\section{METHOD}

\section{Context}

The method section can go any number of different directions, depending on the type of research you conducted, however, it must at least contains research design, data, data collection technique and validity, and data analysis technique. The method used should be accompanied by references and relevant modification should be explained. Procedure and data analysis techniques should be emphasized to a literature review article. The research stages should be clearly stated. The study was qualitative research. Qualitative research was a naturalistic approach that aims at interpreting event(s) in particular contexts and settings, such as "real-world setting (where) the researcher does not try to manipulate the event of interest" Patton (2001).

\section{Participants}

This qualitative study presents a descriptive comparative analysis of two kinds of written data of refusal strategies generated from two groups of participants: (1) Javanese Pre-service English Teacher, referred to hereafter as JPET $(n=10)$ and (2) Sumatranese Pre-Service English Teacher referred to hereafter as SPET $(n=10)$. The ages of the research participants were between 22-35 years. All of them were graduate students consisting of female students $(n=13)$ and male students $(n=7)$. A random sampling technique was carried out to select the participant.

This study presented a descriptive comparative analysis of two kinds of written data of refusal strategies generated from two groups of participants: (1) Javanese Pre-service English Teacher, referred to hereafter as JPET $(n=10)$ and (2) Sumatrans Pre-Service English Teacher referred to hereafter as SPET $(n=10) .13$ female students and 7 male students of the graduate-level participated in this study. Their ages ranged between 22-35 years old. A convenient sampling technique was carried out to select the participant.

\section{Instrument}

This study utilized a set of written responses discourse completion tasks (DCT) to obtain the data. Wijayanto (2019) defines DCTs as "short written descriptions of scenarios, followed by a short dialogue between one participant in the scenarios, whose utterances were provided verbatim, and the research informants, whose utterances were left entirely blank". The informants were asked to write in the gaps that they would say. The DCT comprises six social situations which vary in the degree of power and acquaintanceship with. The research instruments are as follows.

To collect the data, a set of written Discourse Completion Tests (DCTs) was distributed to the participants. Wijayanto (2019) defines DCTs as "short written descriptions of scenarios, followed by a short dialogue between one participant in the scenarios, whose utterances were provided verbatim, and the research informants, whose utterances were left entirely blank". The informants were asked to write in the gaps that they would say in a given situation. The participants acted as a refuser with different social status (lower, equal, and higher). The DCTs provided two initiating acts of refusals, i.e. request and suggestion as to the prompts of refusals. The research instruments were as follows.

Situation 1. You have a lot of tasks. Your friend asks you to fill in his questionnaire. However, you refuse it.

Friend: "It's terrible! I have to accomplish my research on three days. I know you have assignments too, but could you please fill in the questionnaires of my research?"

You say: ...

Situation 2. You are a second-semester student. Your junior (first-semester student) asks you for previous semester test items that you did in the first semester. Nevertheless, you refuse it. 
Junior: "Oh my God! Tomorrow I have an exam on the X course. I am not well prepared for it. I heard that you got an A in this course. Could you tell me the previous semester test items?"

You say: ...

Situation 3. Your lecturer asks you to submit your assignment before the deadline. However, you have another plan to do. Hence, you refuse to submit it.

Lecturer: "Can you submit your assignment a week before the deadline?"

You say: ...

Situation 4. Your friend asks you to take a rest because you look so tired from doing your assignments for the past two days. Nonetheless, you refuse it.

Friend: "You look so pale. Why don't you take a rest for a day?"

You say: ...

Situation 5. You have discussed your thesis proposal with your first supervisor. Then, you consult it with your second supervisor. S/he asks you to change your topic because your topic is too common. However, you refuse it.

Lecturer: "There is no novelty on your thesis proposal. Why don't you expose something new?"

You say: ...

Situation 6. You understand the X course better than your friends do. Your junior has a problem in understanding that course. So, he asks you to teach him about that course. You refuse it.

Junior: "I don't understand about the X course. Could you explain how does X course discuss about?"

You say: ...

The data were collected through online DCTs. The participants were given a link to online DCTs and were asked to answer each situation provided in DCTs using English. The participants were given an explanation related to the situation provided in the DCTs. After the written responses were collected, the responses were coded using Campillo et al (2009).

Adopting Campillo et al.'s (2009) taxonomy, the refusal strategies in this study were classified according to the types of semantic formulas (the main utterances to perform refusals) and adjuncts (utterances which do not express refusals but they go with semantic formulas to provide particular effects to given refusals). Refusals could be expressed directly and indirectly. The following table shows the Campillo et al. (2009) refusal taxonomy.

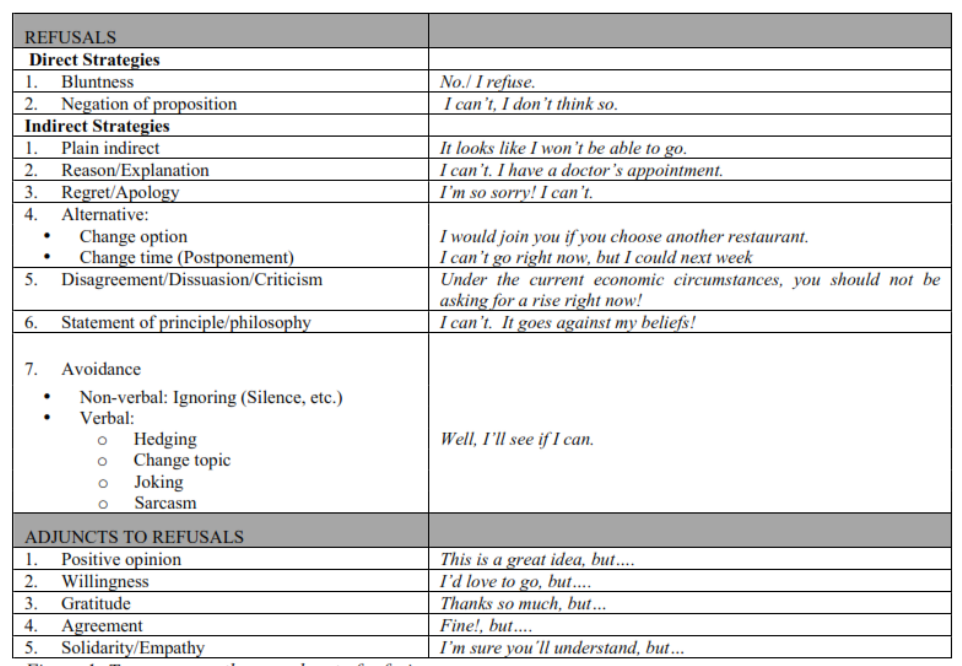

Figure 1. Refusal Taxonomy (Campillo, 2009) 


\section{Procedure}

The researchers distributed the DCT to the participants via online form. Before filling the DCT, the participants were given brief background knowledge of refusal and the classification of refusal strategies according to Campillo et al. Then the participants were given enough time to complete the DCT. Data from all the participants were collected in a day.

The researchers distributed the DCTs to the participants via online form. The participants were given a link to complete online DCTs and were asked to answer each situation provided in DCTs using English. Before filling the DCTs, the participants were given brief background knowledge of refusal and the classification of refusal strategies according to Campillo et al (2009). As the participants answered the online DCTs, they had to respond as if they experienced the given situations. The participants were given enough time to complete the online DCTs. After the written responses were collected, the responses were coded using Campillo et al (2009).

\section{Data Analysis}

Participants' responses to each scenario in DCT were analyzed with the help of classification of refusal strategies according to Campilo et al. First, the content of the responses was classified based on Campilo's taxonomy to find out which strategies were used by participants while refusing to different interlocutors who had different social status. Then the frequency and the percentages of the total refusal strategies employed by the participants are calculated to see the most common refusal strategies used by the participants but firstly the researchers made 3 classification based on the social status namely higher power, equal power and lower power so that the researchers were able to compare the refusal strategies used by the participants based on social status.

Participants' responses to each scenario in DCTs were analyzed with the help of classification of refusal strategies according to Campilo et al (2009). First, the content of the responses was classified based on Campilo's taxonomy. Following Wijayanto (2019), initially, the refusal strategies from the participants were categorized according to the types of semantic formulas (the main utterances to perform refusals) and adjuncts (utterances which do not express refusals but they go with semantic formulas to provide particular effects to given refusals). The semantic formulas and adjuncts included in each refusal response were arranged and identified by tags in a sequential arrangement, for example, "mmm... sorry, I'd love to go, but I have to finish my assignment" was coded as filler + regret/apology + willingness + reason/explanation. In analyzing the responses, if the same semantic formulas or adjuncts occurred more than once, they were counted as their appearances. For example, regret/apology + plain indirect + reason/explanation, + regret/apology, the strategies regret/apology was counted twice. By analyzing the responses, the refusal strategies employed by both groups could be identified. Then, the frequency and the percentages of the total refusal strategies employed by the participants are calculated to see the most frequent refusal strategies used by the participants. The following table shows the Campillo et al (2009) refusal taxonomy.

\section{RESULT}

Situation 1 in below explained about refusing a request to an equal status (refusing to fill out a friend's questionnaire). In refusing a request to a friend, both JPETs and SPETs employed direct and indirect refusal strategies. The chart shows that apology is the most frequent strategy used by both JPETs and SPETs. However, JPETs employed this strategy more often. The JPETs were more frequent in using apology and reason, whereas SPETs were more frequently to use direct strategy, give an alternative, and say adjunct. Moreover, there is an indirect strategy that was only employed by the JPET namely plain indirect strategy. Thus, in this situation, the JPETs were more indirect than SPETs. The JPETs tended to say sorry then explained their reason to refuse the request while SPETs tended 
to directly say that they could not do the request then gave the alternative like changing the time or option. There were two kinds of adjunct used in this situation namely willingness and positive opinion. Willingness strategy was more frequently used by SPETs. Meanwhile, a positive opinion strategy was used by JPETs.

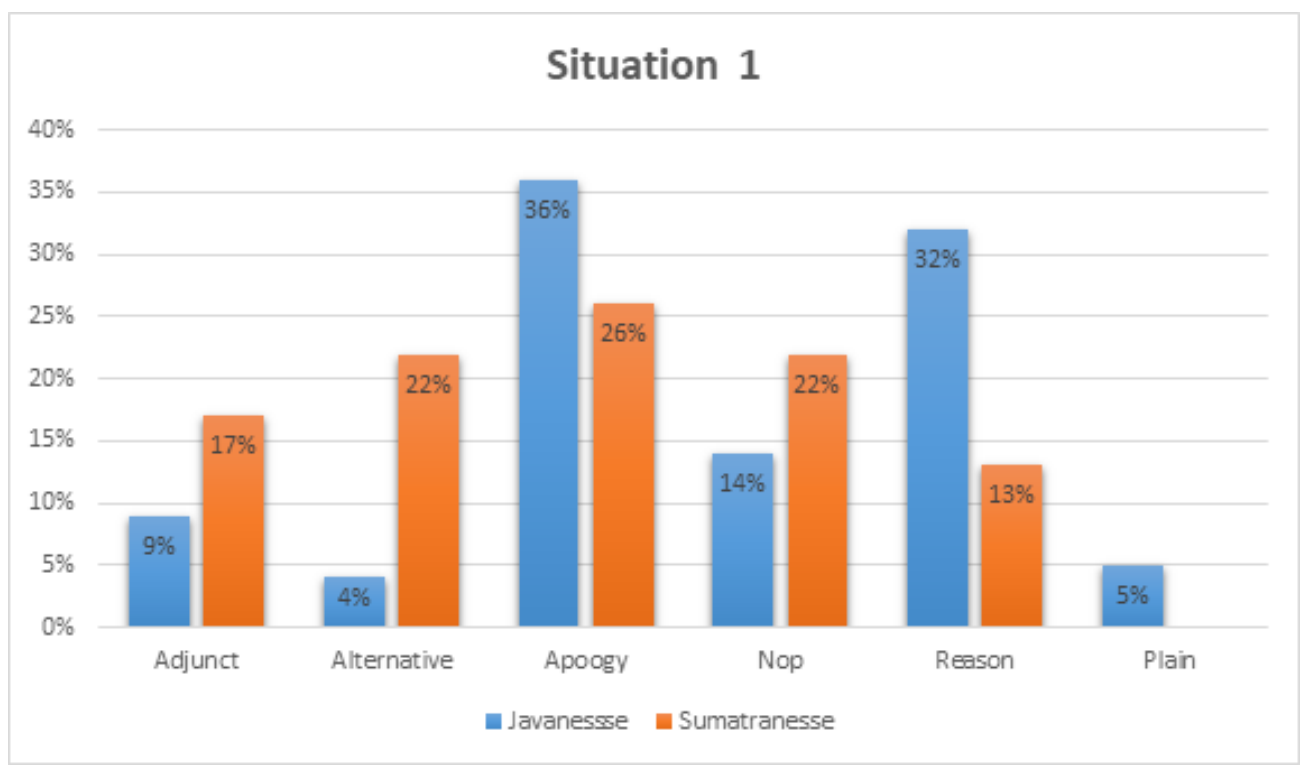

Figure 2. Chart of Refusal Strategies used in Situation 1 by JPETs and SPETs

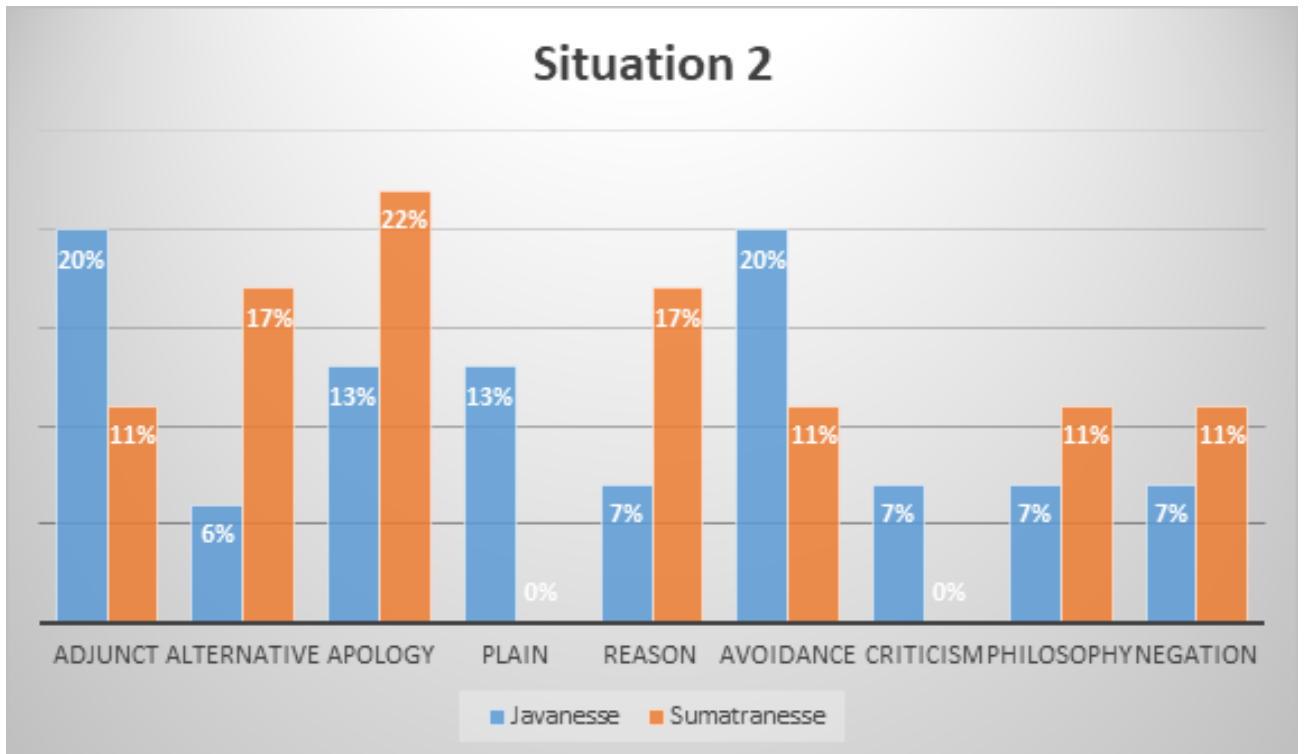

Figure 3. Chart of Refusal Strategies used in Situation 2 by JPETs and SPETs

Situation 2 provides refusing request to a lower status. For refusing a request to a lower status, both JPETs and SPETs employed various refusal strategies from direct and adjunct to refusal. JPETs employed more various strategies rather than SPETs, while SPETs employed more refusal strategies in each situation rather than JPETs. Some strategies that JPETs employed but SPETs did not employ were adjunct (positive opinion) and criticism. The chart shows that apology was the most frequent strategy used by both JPETs and SPETs. However, JPETs employ this strategy more often. 


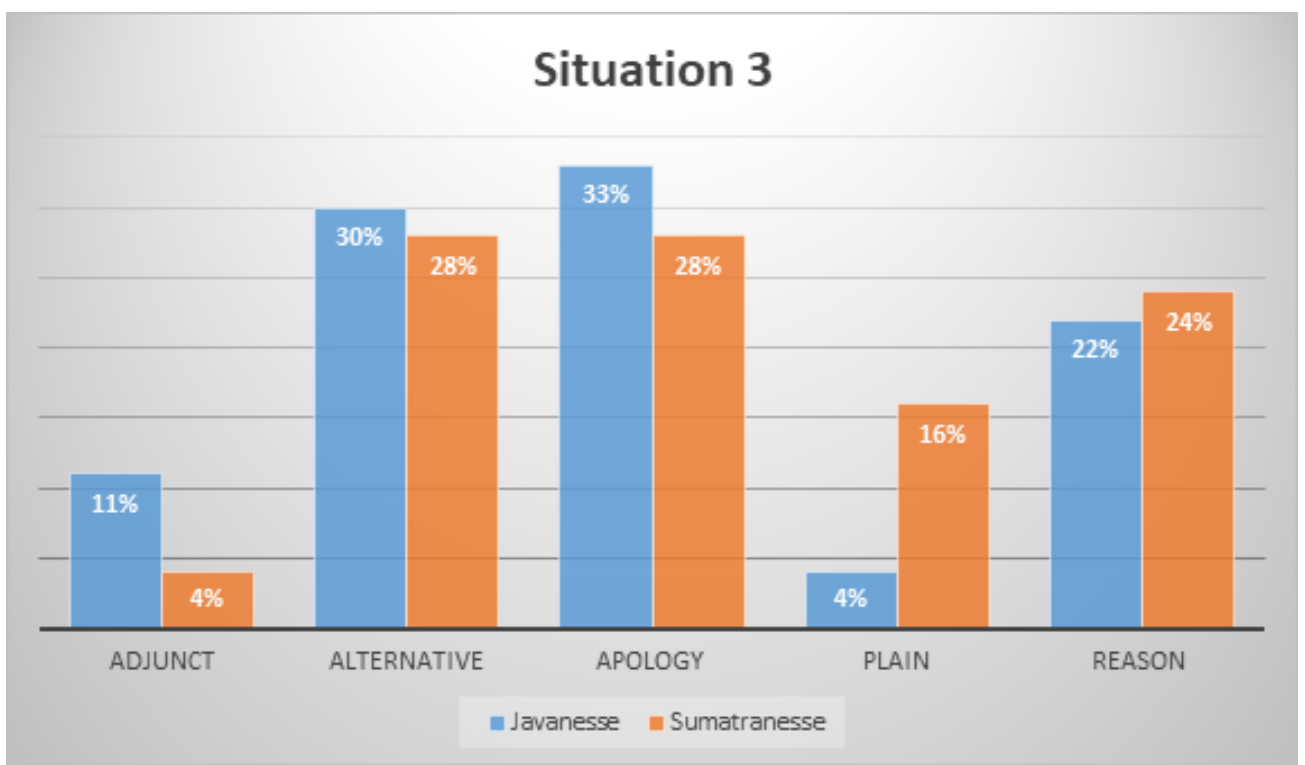

Figure 4. Chart of Refusal Strategies used in Situation 3 by JPETs and SPETs

Situation 3 describes a high power one (a lecturer) request a lower power one (a student) to do a thing (submitting the assignment before the due date). After analyzing the data, it is obtained that JPETs used regret strategy more often than SPETs. The alternative strategy (changing option) places the second strategy that frequently used by both JPETs and SPETs. This strategy followed by providing reason/explanation used by JPETs and SPETs. The plain indirect strategy was used by both categories. However, the SPETs used more often plain indirect strategy than JPET. Both categories also employed some adjuncts namely adjunct of willingness. JPETs used this adjunct more often than the SPETs. However, the positive opinion adjunct was only used by SPETs while the gratitude adjunct was only used by JPETs.

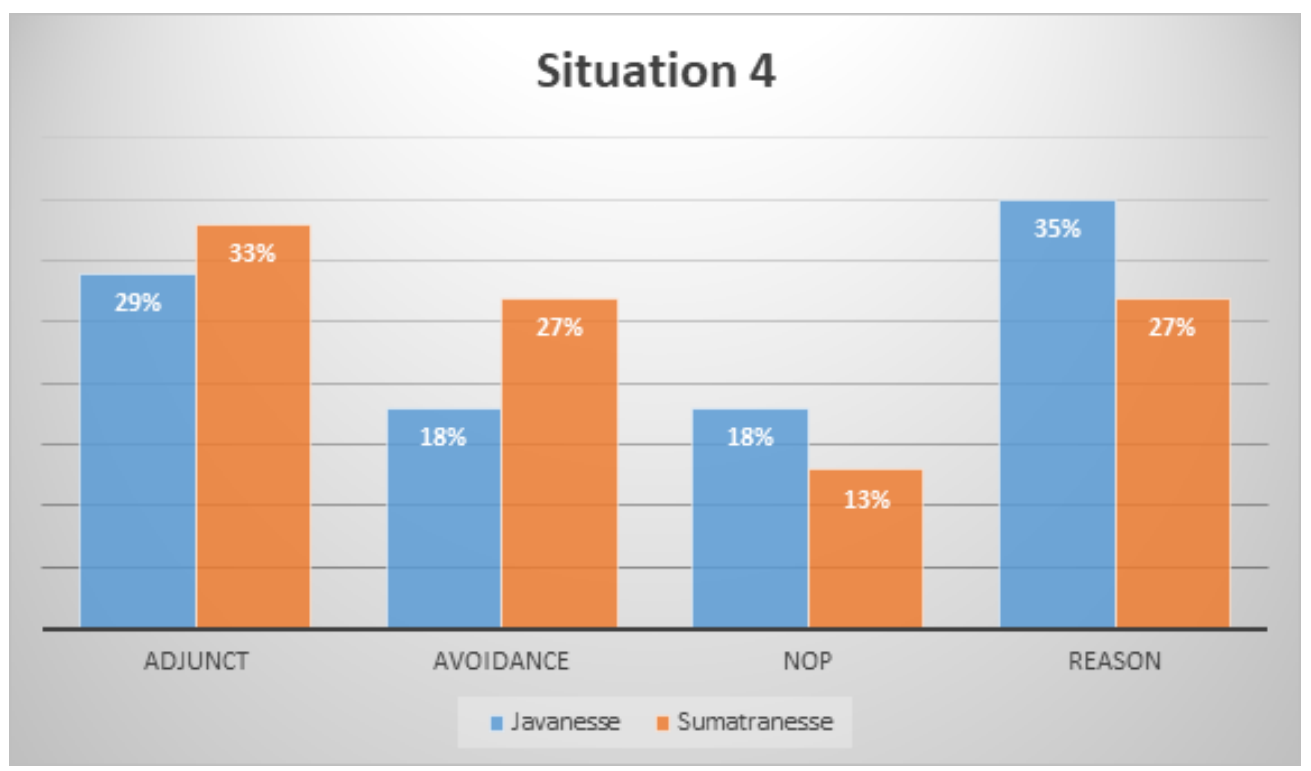

Figure 5. Chart of Refusal Strategies used in Situation 4 by JPETs and SPETs

Situation 4 is about refusing a request to an equal status (refusing a friend's request to take a rest). Both direct and indirect refusal strategies were applied by both JPETs and SPETs. In this situation, 4 refusal strategies are applied namely adjunct, avoidance, the negation of proposition (direct refusal) and reason. The most frequently used strategies 
are adjunct and reason. The JPETs used reason more often than SPETs while SPETs used adjunct more often than JPETs. The adjunct strategies found in this situation were willingness, positive opinion, and gratitude. The gratitude strategy was used to show that the speaker was grateful due to the attention given by the interlocutor.

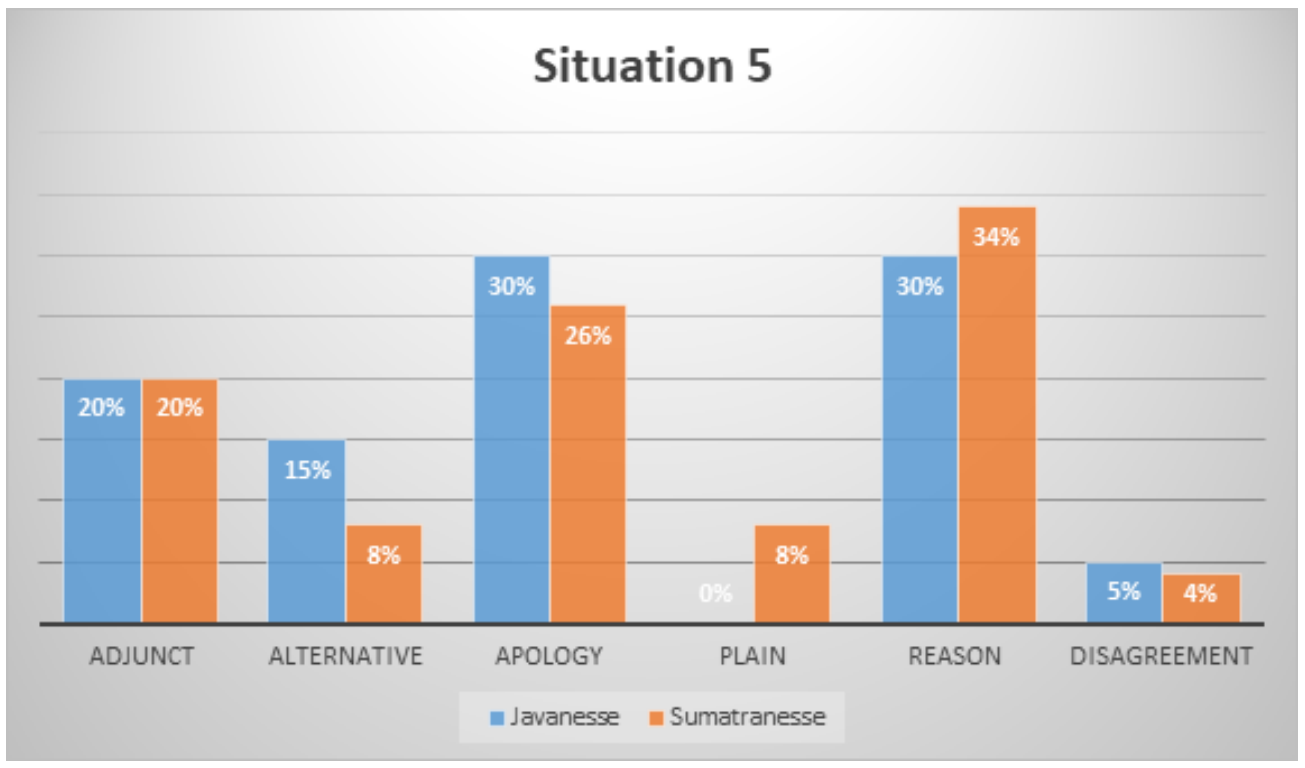

Figure 6. Chart of Refusal Strategies used in Situation 5 by JPETs and SPETs

In situation 5, the high power one (a lecturer) suggested to a lower one (a student) regarding to thesis proposal. Based on the analysis, the JPETs and SPETs mostly used reason/explanation strategy. The regret/apology strategy was in second place for both JPETs and SPETs. Both JPETs and SPETs used adjunct in an equal percentage. However, the types of adjunct used were different. The types of adjunct used will be elaborated in the discussion section. The JPETs used an alternative strategy and disagreement more frequent than the SPETs. However, the plain indirection strategy was only used by the SPETs.

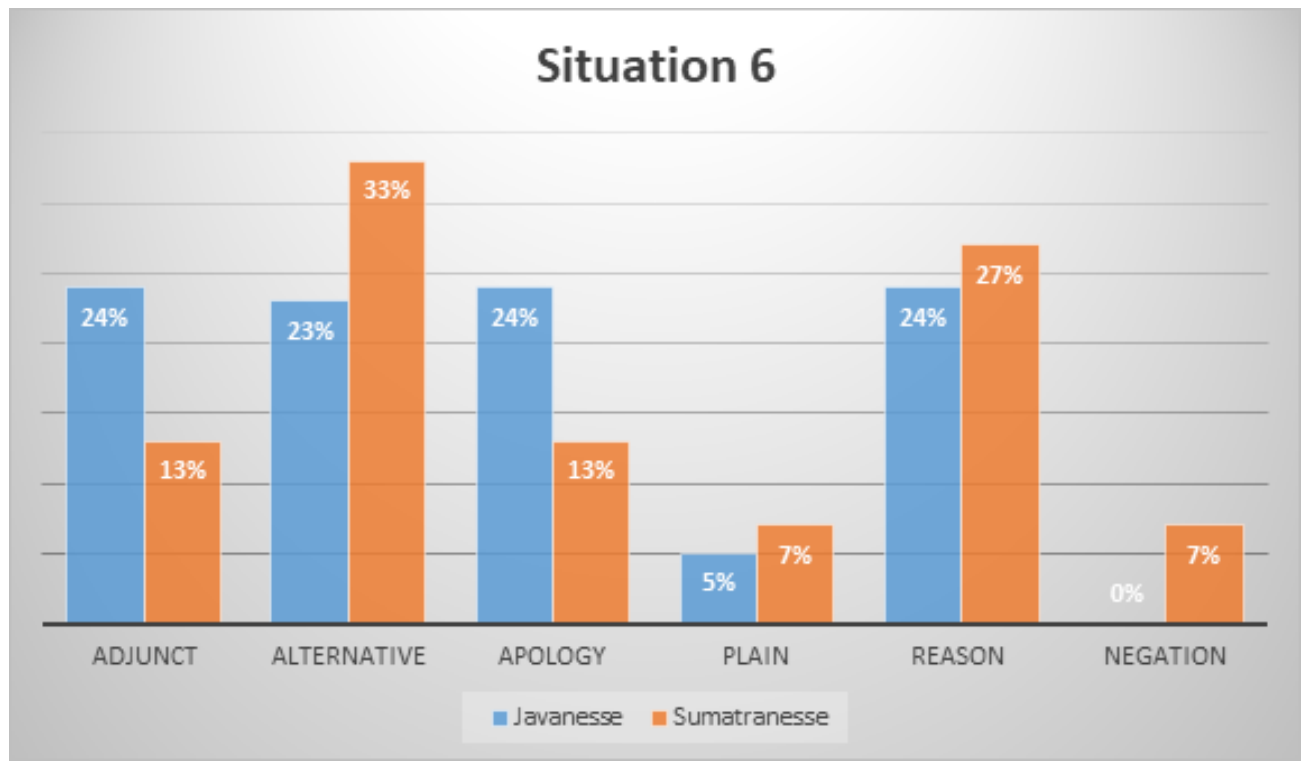

Figure 7. Chart of Refusal Strategies used in Situation 6 by JPETs and SPETs 
Situation 6 provides the lower power (a junior) asks for help. Based on the analysis, JPETs mostly used apology, reason, and adjunct strategies to refuse the junior request. Following these strategies, the alternative and plain indirection were slightly used by the JPETs. While the SPETs mostly used alternative strategy and followed by reason strategy. The adjunct and plain indirectness had equal percentage for SPETs. SPETs also used plain indirection strategy to refuse the request. Nonetheless, only the SPETs used the negation of proportion in delivering refusal.

Based on the chart above, it shows that Javanese mostly used regret to refuse a high power one. They tended to apologize first then provide alternative options in refusing the request. While the Sumatrans mostly used alternative options and regret to deliver the refusal. However, the percentage of regret used by Javanese and Sumatrans were different. The Javanese (33,33\%) and Sumatrans (28\%) indicated that Javanese were politer than the Sumatranese as they used a mitigating device more often.

Basically, in refusing a request to an equal power interlocutor, both JPETs and SPETs employed similar strategies. They combined direct strategy namely the negation of proposition and indirect strategies such as adjunct, alternative, apology, avoidance, reason, and plain indirect. The JPETs were more indirect than SPETs. The JPETs tended to say sorry then explain their reason to refuse the request while SPETs tended to directly say that they could not do the request then give the alternative like changing the time or option. Besides, SPETs used avoidance strategy more often than JPETs. The avoidance here was used for ignoring what the interlocutor had been said by changing the topic, joking or sarcasm.

In refusing a request to a higher power interlocutor, both JPETs and SPETs only employed indirect strategy. The strategies were adjunct, alternative, apology, disagreement, plain indirect, and reason. In contrast with the use of reason strategy in refusing equal power, in refusing a higher power interlocutor the reason strategy was used more frequently by JPETs. Adjunct and alternative strategies were frequently used by the JPETs. It was also contradictory to the strategies used in refusing a request from an equal status interlocutor.

In refusing a request to a lower power interlocutor, both JPETs and SPETs employed direct and indirect strategy. The direct strategy was the negation of proposition. Meanwhile, the indirect strategies were adjunct, alternative, apology, avoidance, criticism, the negation of proposition, plain indirect, reason, and statement of philosophy. Thus, all indirect strategies were applied in refusing a request to lower power interlocutors.

\section{DISCUSSION}

From the findings, it was clear that both JPETs and SPETs employed similar strategies in refusing a request to an equal power interlocutor. They combined direct strategy namely the negation of proposition and indirect strategies such as adjunct, alternative, apology, avoidance, reason, and plain indirect. The JPETs were more indirect than SPETs. The JPETs tended to say sorry then explain their reason to refuse the request while SPETs tended to directly say that they could not do the request then give the alternative like changing the time or option. Besides, SPETs used avoidance strategy more often than JPETs. The avoidance here was used for ignoring what the interlocutor has been said by changing the topic, joking or sarcasm.

In refusing a request to a higher power interlocutor, both JPETs and SPETs only employed indirect strategy. It was in line with Chojimah (2015) in her finding that Indonesian mostly used indirect manner. The strategies were adjunct, alternative, apology, disagreement, plain indirect and reason. In contrast with the use of reason strategy in refusing the equal power, in refusing a higher power interlocutor the reason strategy was used more frequently by JPETs. Adjunct and alternative strategies were frequently used 
by the JPETs. It was also contradictory to the strategies used in refusing a request from an equal status interlocutor.

In refusing a request to a lower power interlocutor, both JPETs and SPETs employed direct and indirect strategy. The direct strategy was the negation of proposition. Meanwhile, the indirect strategies were adjunct, alternative, apology, avoidance, criticism, the negation of proposition, plain indirect, reason, and statement of philosophy. Thus, all indirect strategies were applied in refusing a request to lower power interlocutor. The apology strategy is used as a mitigation device so that it will not hurt the interlocutor. It also will make the speaker is seen as a polite person. "In English, the polite language may be characterized by the use of indirect speech, the use of respectful forms of address systems, e.g. Sir, Madam, or the use of formulaic utterances, e.g. please, excuse me, sorry, thank you, etc." (Fauziati, 2016). This indication were collaborated with Ilmiani et al (2016) and Wijayanto (2019).

The adjunct strategy was used in refusing a request to an equal status, lower status and a higher status. It is used to show that it was not their desire for not complying with the request. Actually, they wanted to do the request but they could not do it. The alternative strategy was used for finding the possibility of complying with the request with a certain condition or option. The alternative was also used in three different levels of power. Besides, the reason strategy was used to show the speaker's situation in the hope that the interlocutor would understand why they cannot comply with the request.

\section{CONCLUSION}

Based on the results, it is known that the most frequently used strategy to refuse is apology followed by reason, alternative, and adjunct. Furthermore, there is a strategy that is used only at lower power and equal power namely avoidance. This strategy is not applied in refusing a request to a higher power interlocutor. All indirect refusal strategies are applied by JPETs and SPETs in refusing to a request. On the other hand, not all direct strategy is applied. The JPETs and SPETs only apply the negation of proposition strategy while bluntness strategy is not applied. The study serves as the consideration for the preservice teachers that they should be aware of the pragmatic competence. Hence, they can introduce pragmatic competence to their future students. However, since this study only includes a small number of participants, future research may be conducted involving larger participants.

\section{REFERENCES}

Bardovi-Harlig, K. (2013). Developing L2 pragmatics. Language Learning, 63(1), 68-96. Beebe, L., T. Takahashi, and R. Uliss-Weltz. (1990). Pragmatic transfer in ESL refusals. In R. Scarcella, E. S. Anderson, and S. Krashen (eds.), Developing Communicative Competence in Second Language. 55-73. New York: Newbury House.

Brown, P. and S. Levinson. (1987). Politeness: Some Universals in Language Use. Cambridge: Cambridge University Press.

Campillo, P. S., Safont-Jordà, M.F. \& Codina-Espurz, V. (2009). Refusal strategies: a proposal from a sociopragmatic approach. Revista Electronica de Lingüistica Aplicada, 8, 139-150.

Codina-Espurz, V. (2013). The role of proficiency in the production of refusals in English in an instructed context. Utrecht Studies in Language and Communication, 25, 121145.

Cohen, A. D. (1996). Speech acts. In S.L. Mackey and N.H. Hornberger (eds.), Sociolinguistics and Language Teaching. 383-420. Cambridge: Cambridge University Press.

Demirkol, T. (2016). How do We Say 'No' in English? Social and Behavioral Sciences, 232 ( 2016$), 792-799$. 
Félix-Brasdefer, J. C. (2008). Perceptions of refusals to invitations: Exploring the minds of foreign language learners. Language Awareness, 17(3), 195-211.

Fauziati, E. (2016). Applied linguistics:principles of foreign language teaching, learning, and researching. Surakarta: Era Pustaka Utama.

Gass, S. and N. Houck. (1999). Interlanguage refusals: a cross-cultural study of Japanese English. New York: Mouton de Gruyter.

Golato, A. (2003). Studying compliment responses: A comparison of DCTs and naturally occurring talk. Applied Linguistics, 24(1), 90-121.

Kasper, G. (2000). Data collection in pragmatics research. In H. Spencery-Oatey (Ed.), Culturally speaking: Managing rapport through talk across cultures, 316-341, New York: Continuum.

Kasper, G. \& Rose, K. R. (2001). Pragmatics in language teaching. New York: Cambridge University Press.

Kondo, S. (2008). Effects of pragmatic development through awareness-raising instruction: Refusals by Japanese EFL learners. In E. Alcón and A. Martínez-Flor (eds.), Investigating Pragmatics in Foreign Language Learning, Teaching and Testing. 153- 177. Clevedon: Multilingual Matters.

Patton, M. Q. (2001). Qualitative research and evaluation methods (3rd ed.). Beverly Hills, CA: Sage.

Wijayanto, A. (2019). Refusals in Javanese and English: A comparative study of saying 'no' in two different cultures. Journal of Intercultural Communication, 50(5), 1404-1634. 